\title{
Optimal Conductor selection and Capacitor Placement for Cost minimization in Distribution Systems
}

\author{
Kollu Ravindra ${ }^{1}$ and KRKV Prasad ${ }^{2}$ \\ ${ }^{1}$ EEE Dept., UCEK, JNTU Kakinada, \\ Kakinada, India \\ ${ }^{2}$ EEE Dept., ACET, \\ Suramplaem, India
}

\begin{abstract}
In this paper conductor selection and capacitor placement is done optimally to minimize system cost. Optimization problem is solved using Harmony search algorithm (HSA) with cost minimization as objective and maximum conductor current capacity as constraints. Both annual energy loss cost and annual capital investment cost for conductors and capacitors are considered for analysis. The proposed approach is implemented on an 85-bus system and results are presented. Results proved that selection of optimal conductor sizes and capacitors simultaneously for the network resulted in reduced losses, cost and improved voltage profile.
\end{abstract}

Keywords: Conductor selection, Capacitor placement, Harmony search algorithm, Cost minimization.

\section{Introduction}

Huge distribution losses and poor voltage profile is a major problem for power distribution systems as they force the distribution companies to incur heavy financial loss. Several loss reduction techniques such as reconfiguration, conductor selection, capacitor placement and distributed generation placement can be employed in the system. Among these conductor selection and capacitor placement are very popular owing to their effectiveness in improving the performance of distribution systems. Placing shunt capacitor of optimal sizes at appropriate locations and choosing optimally the conductor sizes for the branches could result in reduced losses and improved voltage profile.

Adel Ali et al. [1] employed loss sensitivity indices to find capacitor locations and Ant Colony optimization algorithm to find optimal capacitor sizes in order to minimize losses and cost. Askarzadeh [2] made use of Crow Search algorithm (CSA) to solve optimal capacitor allocation problem considering cost minimization as objective. Plant growth search algorithm is used for capacitor placement for loss reduction and voltage profile improvement [3]. Ranjan et al. [4] used an evolutionary programming technique to optimally allocate capacitors in distribution systems with an objective to minimize energy loss cost and investment cost. Raju et al. [5] developed a heuristic algorithm for optimal capacitor placement in a agricultural feeder to minimize system cost. Rao et al. [6] used Harmony search algorithm with differential operator (HSDE) to solve optimal capacitor allocation problem to minimize cost. Abdelaziz and Ahmed [7] used CSA and Sherif at al. [8] used Grass hopper algorithm to optimally allocate capacitors to minimize operating cost and investment cost of system. In this work optimal conductor selection and capacitor placement is done simultaneously to maximize the both technical and economical benefits. The paper is structured as follows: Section II discusses problem formulation, HSA and proposed approach of simultaneous optimal capacitor placement and conductor selection, Section III presents results, and Section IV outlines conclusions.

\section{Problem Formulation}

A. Mathematical model

Objective function for optimal conductor and capacitor selection in a radial distribution system is given as

$$
\begin{aligned}
& \text { Cost }=\operatorname{minimize}\left(C_{I}+C_{E L}\right) \\
& C_{I}=C_{I, \text { con }}+C_{I, \text { cap }}
\end{aligned}
$$




$$
\begin{gathered}
C_{I, \text { cap }}=\sum_{i=1}^{n}\left(\alpha_{C} K_{f}+K_{i}^{c} Q_{i}^{c}\right) \\
C_{I, \text { con }}=\sum_{i=1}^{b r} \alpha \times \text { con_area }^{t} \times C \times \text { len }_{i} \\
C_{E L}=\sum_{i=1}^{b r}\left(K_{p} \operatorname{loss}_{i}+K_{E} \times \operatorname{loss}_{i} \times T \times L S F\right)
\end{gathered}
$$

where $C_{I}$ is the total annual capital investment cost (Rs.), $C_{I, \text { con }}$ is the annual investment cost associated with conductor selection (Rs.), $C_{I, \text { cap }}$ is the annual investment cost associated with capacitor placement (Rs.), $C_{E L}$ is the annual energy loss cost (Rs.), $K_{f}$ corresponds to the fixed cost of capacitor (Rs.), $K_{i}^{c}$ is the annual installation cost of capacitor (Rs./kVAr), $Q_{i}^{c}$ is the capacitor size (kVAr), $\alpha$ and $\alpha_{\mathrm{c}}$ are the interest and depreciation factor [4] associated with conductor selection and capacitor selection respectively, con_area ${ }^{t}$ is type ' $t$ ' conductor crosssection area $\left(\mathrm{mm}^{2}\right), C$ is the conductor cost (Rs. $\left./ \mathrm{mm}^{2} / \mathrm{Km}\right)$, len $_{i}$ is the length of conductor of $i^{t h}$ branch $(\mathrm{Km}), n$ corresponds to number of capacitors to be placed, $b r$ represents number of branches, $K_{p}$ is the levelized annual demand cost (Rs./kW), $\operatorname{loss}_{i}$ is loss in the $i^{\text {th }}$ branch $(\mathrm{kW}), K_{E}$ is the energy cost (Rupees/kWh), $T$ is the number of hours per annum, $L S F$ is loss factor. Objective function is minimized subjected to the equality and inequality constraints. Equality constraints: Real and reactive power flow balance at each node is the constraint [9].

Inequality constraints:

$$
\begin{aligned}
& Q_{C, \text { min }} \leq Q_{C, k} \leq Q_{C, \text { max }} \\
& Q_{C, \text { Total }}<Q_{D, \text { Total }}
\end{aligned}
$$

Where $Q_{C, k}$ : represents capacitor size (kVAr), $Q_{C, \text { min }}$ corresponds to minimum capacitor size (kVAr), $Q_{C, \max }$ corresponds to maximum capacitor size (kVAr), $Q_{C \text {, Total }}$ represents the total size of all installed capacitor $(\mathrm{kVAr}), Q_{D \text {,Total }}$ represents the total reactive power demand $(\mathrm{kVAr})$.

$$
\mathrm{I}_{\mathrm{i}} \leq \mathrm{I}_{\mathrm{i}, \max }
$$

where $I_{i, \max }$ is the current limit of $i^{\text {th }}$ branch, $I_{i}$ is the current flow in $i^{\text {th }}$ branch.

\section{B. HSA}

HSA is inspired by the natural phenomena of musicians' behavior. HSA is very efficient in solving optimization problem. Steps of HSA are explained briefly below. Detailed explanation can be found in [9].

\section{1) Defining the problem and choosing of HSA}

\section{Parameters}

$$
\begin{aligned}
& \text { Minimize } f(z) \\
& \text { Subject to } z_{i} \in Z, \quad i=1,2, \ldots \ldots . . N
\end{aligned}
$$

where, $f(z)$ corresponds to the objective function; $z$ corresponds to the set of decision variable $z_{i} ; N$ represents the number of decision variables, $z_{i}$ has to be initialized between the lower and upper bounds for each decision variable.

Harmony Memory Size (HMS) corresponds to number of solution vectors; Harmony Memory Considering Rate (HMCR); Pitch Adjusting Rate $(P A R)$; and maximum number of iterations $\left(\right.$ Iter $\left._{\max }\right)$. The harmony memory $(H M)$ is the memory in which all the solution vectors are stored.

\section{2) Initialization}

$H M$ is filled with randomly generated vectors as shown in (7)

$$
H M=\left[\begin{array}{ccccc}
z_{1}^{1} & z_{2}^{1} & . . & z_{N-1}^{1} & z_{N}^{1} \\
z_{1}^{2} & z_{2}^{2} & . . & z_{N-1}^{2} & z_{N}^{2} \\
\mathrm{M} & \mathrm{M} & \mathrm{M} & \mathrm{M} & \mathrm{M} \\
z_{1}^{H M S-1} & z_{2}^{H M S-1} & . . & z_{N-1}^{H M S-1} & z_{N}^{H M S-1} \\
z_{1}^{H M S} & z_{2}^{H M S} & . . & z_{N-1}^{H M S} & z_{N}^{H M S}
\end{array}\right]
$$

\section{3) Improvisation}

A new vector is 'generated using Memory consideration. New vector is selected from the existing vectors present in $H M$ with a probability of $H M C R$, while a new vector is generated randomly with a probability of (1-HMCR). For the new vector which is generated using memory consideration, pitch adjustment is done with a probability of $P A R$.

4) Update harmony memory

A new vector is included in to the $H M$ if its fitness is better than the worst vector in HM by excluding the worst vector.

\section{5) Check termination criterion \\ Steps 3 and 4 are repeated iter $_{\text {max }}$ times.}

\section{Proposed Approach}

Step1: Define cost as objective function, capacitor sizes and locations, branch conductor type as decision variables. Initialize HSA parameters and specify the 85-bus test system line and load data, available conductor types and capacitor sizes, other cost related data. 
Step2: Initialize the HM with solution vectors. A typical solution vector is given by (7)

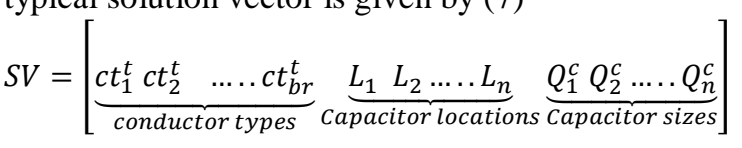

where $c t_{b r}^{t}$ corresponds to the conductor type used for a branch, $L_{n}$ corresponds to capacitor location.

Determine the objective function value specified in (1) corresponding to each solution vector in $H M$ by running load flow. Forward-Backward sweep load flow method is used in this work. Sort the solution vectors in $H M$ based on their ascending order of functional values.

Step3: Improve the HM as discussed in previous section.

Step4: Update the HM

Step5: Check the termination criteria and stop.

\section{Results}

To verify the efficacy of the proposed approach, it is tested on 85-bus system which is an $11 \mathrm{kV}$ system whose data is taken from [10]. HSA parameters chosen for this work are: HMS $=50$, iter ${ }_{\max }=300$, par=0.3, HMCR $=0.9$. Conductor types and their technical data are given in Table 1 [8]. Capacitor sizes available and their annual installation cost are referred from [4].Other parameters chosen are $K_{f}=\$$ $1000, \alpha=0.1$ as conductor life is considered to be 25 years, $\alpha_{c}=0.15$ as capacitor bank life is considered to be ten years, $C=$ Rs. $\left.500 / \mathrm{mm}^{2} / \mathrm{Km}\right), \quad K_{p}=$ Rs. $4000 / \mathrm{kW}, K_{E}=\mathrm{Rs} .5 / \mathrm{kWh}, T=8760, L S F=0.2$.

TABLE1 Conductors technical data

\begin{tabular}{|l|l|l|l|l|l|}
\hline $\begin{array}{l}\text { Type } \\
\text { no. }\end{array}$ & $\begin{array}{l}\text { Area } \\
(\mathrm{mm} 2)\end{array}$ & $\mathrm{R}(\Omega / \mathrm{km})$ & $\mathrm{X}(\Omega / \mathrm{km})$ & $\mathrm{I}_{\max }(\mathrm{A})$ & $\begin{array}{l}\text { Conductor } \\
\text { name }\end{array}$ \\
\hline 1 & 13 & 1.3760 & 0.3896 & 115 & Squirrel \\
\hline 2 & 16 & 1.098 & 0.310 & 138 & Gopher \\
\hline 3 & 20 & 0.9108 & 0.3797 & 150 & Weasel \\
\hline 4 & 25 & 0.6795 & 0.298 & 180 & Ferret \\
\hline 5 & 30 & 0.5441 & 0.3673 & 208 & Rabbit \\
\hline 6 & 40 & 0.4565 & 0.2850 & 226 & Mink \\
\hline 7 & 45 & 0.3841 & 0.2795 & 250 & Beaver \\
\hline 8 & 48 & 0.3657 & 0.3579 & 270 & Raccoon \\
\hline
\end{tabular}

Three scenarios are simulated in this work.

Scenario I: System without optimal conductor selection and capacitor placement (Base case).

Scenario II: System without optimal conductor selection only.

Scenario III: System with optimal conductor selection and capacitor placement (Proposed approach).
TABLE 2 Results of 85-bu system

\begin{tabular}{|c|c|c|c|}
\hline Branch no. & $\begin{array}{c}\text { Scenario I } \\
\text { (Conductor } \\
\text { type) }\end{array}$ & $\begin{array}{c}\text { Scenario II } \\
\text { (Conductor type) }\end{array}$ & $\begin{array}{c}\text { Scenario III } \\
\text { (Conductor } \\
\text { type) }\end{array}$ \\
\hline 1 & 8 & 8 & 8 \\
\hline 2 & 8 & 8 & 8 \\
\hline 3 & 8 & 8 & 8 \\
\hline 4 & 8 & 8 & 8 \\
\hline 5 & 8 & 8 & 8 \\
\hline 6 & 8 & 8 & 8 \\
\hline 7 & 8 & 8 & 8 \\
\hline 8 & 1 & 8 & 8 \\
\hline 9 & 1 & 8 & 8 \\
\hline 10 & 1 & 7 & 8 \\
\hline 11 & 1 & 8 & 7 \\
\hline 12 & 1 & 7 & 5 \\
\hline 13 & 1 & 3 & 2 \\
\hline 14 & 1 & 5 & 3 \\
\hline 15 & 1 & 4 & 2 \\
\hline 16 & 1 & 8 & 5 \\
\hline 17 & 1 & 8 & 8 \\
\hline 18 & 1 & 5 & 7 \\
\hline 19 & 1 & 4 & 5 \\
\hline 20 & 1 & 4 & 2 \\
\hline 21 & 1 & 2 & 4 \\
\hline 22 & 1 & 2 & 4 \\
\hline 23 & 1 & 1 & 2 \\
\hline 24 & 1 & 8 & 8 \\
\hline 25 & 1 & 8 & 8 \\
\hline 26 & 1 & 8 & 8 \\
\hline 27 & 1 & 8 & 8 \\
\hline 28 & 1 & 8 & 7 \\
\hline 29 & 1 & 7 & 6 \\
\hline 30 & 1 & 8 & 6 \\
\hline 31 & 1 & 8 & 7 \\
\hline 32 & 1 & 8 & 7 \\
\hline 33 & 1 & 7 & 5 \\
\hline 34 & 1 & 7 & 6 \\
\hline 35 & 1 & 1 & 4 \\
\hline 36 & 1 & 1 & 7 \\
\hline 37 & 1 & 7 & 2 \\
\hline 38 & 1 & 2 & 4 \\
\hline 39 & 1 & 5 & 5 \\
\hline 40 & 1 & 1 & 4 \\
\hline 41 & 1 & 1 & 7 \\
\hline 42 & 1 & 2 & 4 \\
\hline 43 & 1 & 5 & 5 \\
\hline 44 & 1 & 5 & 5 \\
\hline 45 & 1 & 5 & 2 \\
\hline 46 & 1 & 2 & 2 \\
\hline 47 & 1 & 6 & 6 \\
\hline 48 & 1 & 7 & 6 \\
\hline 49 & 1 & 6 & 4 \\
\hline 50 & 1 & 6 & 6 \\
\hline 51 & 1 & 6 & 5 \\
\hline 52 & 1 & 5 & 4 \\
\hline 53 & 1 & 3 & 6 \\
\hline 54 & 1 & 2 & 6 \\
\hline 55 & 1 & 1 & 4 \\
\hline 56 & 1 & 7 & 8 \\
\hline 57 & 1 & 8 & 8 \\
\hline 58 & 1 & 4 & 5 \\
\hline 59 & 1 & 8 & 8 \\
\hline 60 & 1 & 6 & 5 \\
\hline 61 & 1 & 3 & 8 \\
\hline 62 & 1 & 7 & 5 \\
\hline 63 & 1 & 8 & 8 \\
\hline 64 & 1 & 4 & 2 \\
\hline 65 & 1 & 1 & 3 \\
\hline
\end{tabular}




\begin{tabular}{|c|c|c|c|}
\hline 66 & 1 & 8 & 7 \\
\hline 67 & 1 & 8 & 7 \\
\hline 68 & 1 & 7 & 7 \\
\hline 69 & 1 & 6 & 2 \\
\hline 70 & 1 & 3 & 5 \\
\hline 71 & 1 & 4 & 3 \\
\hline 72 & 1 & 5 & 3 \\
\hline 73 & 1 & 4 & 4 \\
\hline 74 & 1 & 2 & 3 \\
\hline 75 & 1 & 8 & 6 \\
\hline 76 & 1 & 6 & 3 \\
\hline 77 & 1 & 4 & 3 \\
\hline 78 & 1 & 1 & 2 \\
\hline 79 & 1 & 7 & 5 \\
\hline 80 & 1 & 4 & 5 \\
\hline 81 & 1 & 2 & 5 \\
\hline 82 & 1 & 2 & 3 \\
\hline 83 & 1 & 1 & 3 \\
\hline 84 & 1 & 4 & 1 \\
\hline \begin{tabular}{|c|} 
Capacitor \\
sizes (at bus \\
number) \\
(MVAr) \\
\end{tabular} & --- & -- & $\begin{array}{l}0.15 \text { (at 52) } \\
1.35 \text { (at 58) } \\
0.75 \text { (at } 30)\end{array}$ \\
\hline \begin{tabular}{|c|} 
Minimum \\
voltage (at \\
bus number)
\end{tabular} & 0.8628 (at 54) & 0.882 (at 54) & 0.9452 (at 54) \\
\hline $\begin{array}{l}\text { Total cost } \\
\text { (Rs.) }\end{array}$ & $40,63,316.18$ & $33,20,081.66$ & $16,03,875.14$ \\
\hline $\begin{array}{c}\text { Cost } \\
\text { reduction } \\
(\%)\end{array}$ & -- & 18.29 & 60.53 \\
\hline $\begin{array}{c}\text { Power loss } \\
(\mathrm{kW})\end{array}$ & 315.6 & 255.02 & 118.14 \\
\hline $\begin{array}{c}\text { Loss } \\
\text { reduction } \\
(\%)\end{array}$ & -- & 19.19 & 62.56 \\
\hline
\end{tabular}

Results obtained for the three scenarios are tabulated in table 2.Proposed approach (Scenario -III) resulted in a percentage cost reduction of 60.53 resulting in considerable savings. Also the percentage loss reduction for Scenario-III is 62.56 compared to 19.19 for Scenario-II. Figure 1, shows that voltage profile of the system has improved considerably for Scenario-III.

\section{Conclusion}

In this work optimal conductor selection along with capacitor placement is done on an 85-bus system with an objective to minimize both annual capital investment cost and annual energy loss cost. The proposed approach resulted in huge cost reduction, loss reduction and voltage profile improvement when compared to the scenario where only optimal conductor selection is done. Voltage profile of the entire system has improved vastly due to deployment of capacitors along with optimal conductor selection for the system branches.

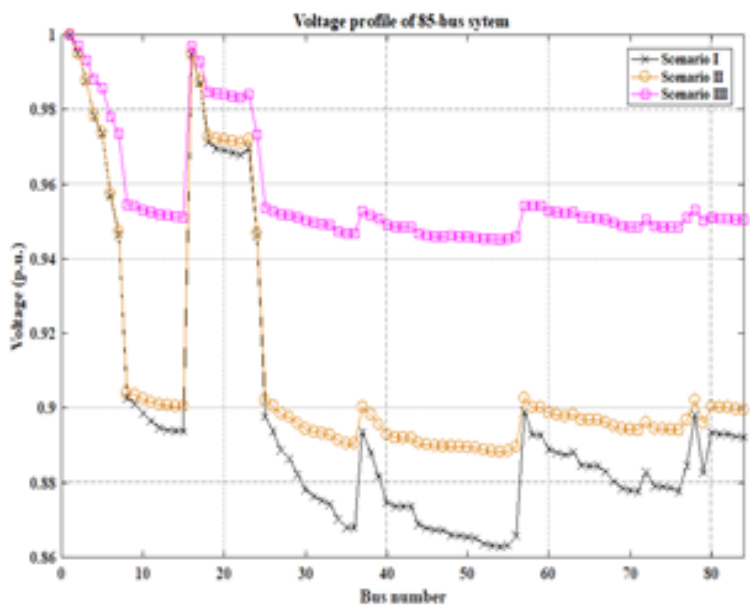

Fig.1 Voltage profile of 85-bus system

\section{References}

[1] A. A. Abou El-Ela, R. A. El-Sehiemy, A. M. Kinawy and M. T. Mouwafi, "Optimal capacitor placement in distribution systems for power loss reduction and voltage profile improvement," in IET Generation, Transmission \& Distribution, vol. 10, no. 5, pp. 1209-1221, 2015.

[2] A. Askarzadeh, "Capacitor placement in distribution systems for power loss reduction and voltage improvement: a new methodology," in IET Generation, Transmission \& Distribution, vol. 10, no. 14, pp. 3631-3638, 2016.

[4] R.Srinivasas Rao, S.V.L. Narasimham, M. Ramalingaraju, "Optimal capacitor placement in a radial distribution system using Plant Growth Simulation Algorithm”, International Journal of Electrical Power \& Energy Systems, vol. 33, no.5, pp.1133-1139, 2011.

[5] R. Ranjan, A. Chaturvedi, P. S. Solanki and D. Das, "Optimal conductor selection of radial distribution feeders using evolutionary programming," TENCON 2003. Conference on Convergent Technologies for Asia-Pacific Region, Bangalore, India, vol.1, pp. 456-459, 2003.

[5] M. Ramalinga Raju, K. V. S. Ramachandra Murthy, K. Ravindra and R. Srinivasa Rao, "Optimal conductor selection for agricultural distribution system - a case study," 2010 International Conference on Intelligent and Advanced Systems, Manila, 2010, pp. 1-6.

[6] Rayapudi Srinivasa Rao, K.Satish, SVL Narasimham, "optimal conductor size selection in distribution systems using the harmony search algorithm with a differential operator", Electric Power Components and Systems, vol.40, no.1, pp.41-56, 2012. 
[7] Almoataz Y. Abdelaziz, Ahmed Fathy,A novel approach based on crow search algorithm for optimal selection of conductor size in radial distribution networks,Engineering Science and Technology, an International Journal, vol. 20, no. 2, pp. 391-402, 2017.

[8] Sherif M. Ismael, Shady H.E. Abdel Aleem, Almoataz Y. Abdelaziz, Ahmed F. Zobaa,Chapter 8 - Optimal Conductor Selection of Radial Distribution Feeders: An Overview and New Application Using Grasshopper Optimization Algorithm,

Classical and Recent Aspects of Power System Optimization,
Academic Press, 2018, pp. 185-217.

[9] Kollu, R., Rayapudi, S. R. and Sadhu, V. L. N, "A novel method for optimal placement of distributed generation in distribution systems using HSDO," International Transactions on Electrical Energy Systems, vol. 24, no. 4, pp. 547-56, 2014.

[10] D. Das, D.P. Kothari, A. Kalam,Simple and efficient method for load flow solution of radial distribution networks, International Journal of Electrical Power \& Energy Systems, vol. 17, no. 5, pp.335-346, 1995. 